\title{
Impact of Emotional Labor on the Turnover Intention of Medical Technology Workers in General Hospital
}

\author{
Jong-Hyun Yang ${ }^{1}$ and An-Sook Park ${ }^{2}$ \\ ${ }^{1}$ Department of Health Administration, Jungwon University, Chungbuk, Korea \\ ${ }^{2}$ Department of Nursing, Jungwon University, Chungbuk, Korea \\ ${ }^{1}$ mybabos@jwu.ac.kr, ${ }^{2}$ pkase2001@jwu.ac.kr
}

\begin{abstract}
This study analyzed the relationship between emotional labor, job satisfaction, organizational commitment, and turnover intention of medical technology workers. A survey was conducted from July 01 to July 31, 2018, for 310 medical technology workers at 10 general hospitals in Korea. The average emotional labor level was $2.82 \pm 0.64$, job satisfaction $3.07 \pm 0.49$, organizational commitment $3.02 \pm 0.57$, and turnover intention $3.23 \pm 0.68$. All levels of emotional labor, job satisfaction, and organizational commitment turned out to be above average. Emotional labor has been shown to have a significantly positive $(+)$ influence on turnover, and monthly salary, job satisfaction, and organizational commitment have a significant negative (-) influence on turnover, respectively. Therefore, hospitals need to reduce the emotional labor of their medical technology workers, thereby increasing job satisfaction and organizational commitment to decrease the turnover intention of their medical technology workers.
\end{abstract}

Keywords: Emotional labor, Turnover intention, Medical technology workers, General hospital

\section{Introduction}

\subsection{The need for research}

Recently, medical institutions are making great efforts to improve the quality of medical services for survival and development due to changes in the domestic and overseas environment, including the increase in the diverse needs of customers, the control of medical fees, the increase in hospitals and the opening of the medical market. Accordingly, hospitals intend to strengthen and urge the stereotyped emotional expression to their staff and to control personal feelings and emotions, as part of strategic efforts to enhance the quality of medical services and customer satisfaction [1].

Emotional labor refers to personal efforts to adjust emotions resulting from the difference between the emotional state experienced by him/her to adapt to an organization and the emotional expressions required by the organization's norms [2]. The medical technology worker's emotional labor has a positive effect on the mental and physical recovery of patients

Article history:

Received (March 26, 2019), Review Result (April 25, 2019), Accepted (May 24, 2019) 
through the formation of relationships with patients. In recent days, the negative aspect of emotional labor has been also emphasized, such as the decrease in job satisfaction and organizational commitment, and the increase in turnover intention, which requires efforts to reduce the level of emotional labor [3]. This study intends to analyze the influence of medical technology workers' emotional labor, job satisfaction, and organizational commitment on turnover rate, and provide basic data for more efficient management of medical technology workers.

\section{Research method}

\subsection{Research targets and data collection}

The purpose of this study was explained to the medical technology workers at 100 general hospitals nationwide, and those who agreed in writing to participate in the survey were subject to this study. Data were collected for the period of 31 days from July 01 to July 31 , 2018, and a total of 310 questionnaires were distributed and 306 copies were returned. Of these, 300 copies were used as the final analysis data, excluding questionnaires with insufficient contents.

\subsection{Analysis method}

The data collected in this study were analyzed using SPSS Statistics 21.0 program as follows: First, the general characteristics of the research targets were analyzed, and the minimum, maximum, mean, and standard deviation were analyzed to get a handle on the degree of emotional labor, job satisfaction, organizational commitment, and turnover intention. Second, t-test and ANOVA were conducted to verify differences in emotional labor, job satisfaction, organizational commitment, and turnover intention according to the general characteristics. Third, Pearson's correlation coefficient was used to examine the relationship among emotional labor, job satisfaction, organizational commitment, and turnover intention. Finally, Hierarchical multiple linear regression was conducted to analyze the effects of general characteristics, emotional labor, job satisfaction, and organizational commitment on turnover intention.

\section{Result of this study}

\subsection{General characteristics of research targets}

The general characteristics of this study are shown in [Table 1]. The large subset was as follows; age: 147 workers from 20-29 years of age (49\%), gender: 162 male workers (54\%), academic background: 171 workers graduated from 4-year-course college (57\%), 177 single workers (59\%), 177 religious workers (59\%), 81 radiologists (27\%), 123 workers below 1-5 years of the work period (41\%), work without shift: 255 (85\%), KRW2-3 million of monthly salary: 135 (45\%) and 156 workers without turnover experience (52\%). 
Table 1. Characteristics of the subject

\begin{tabular}{|c|c|c|}
\hline Characteristics & Categories & $\mathrm{N}(\%)$ \\
\hline \multirow{3}{*}{ Age(year) } & $20-29$ & $147(49)$ \\
\hline & $30-39$ & $99(33)$ \\
\hline & $\geq 40$ & $54(18)$ \\
\hline \multirow{2}{*}{ Gender } & Male & $162(54)$ \\
\hline & Female & $138(46)$ \\
\hline \multirow{3}{*}{ Education } & 3 yr college & $84(28)$ \\
\hline & University & $171(57)$ \\
\hline & Master & $45(15)$ \\
\hline \multirow{2}{*}{ Marital status } & Not married & $177(59)$ \\
\hline & Married & $123(41)$ \\
\hline \multirow{2}{*}{ Religion } & Have & $177(59)$ \\
\hline & Don't have & $123(41)$ \\
\hline \multirow{4}{*}{ Type of jobs } & Radiologist & $81(27)$ \\
\hline & Medical laboratory technologist & $60(20)$ \\
\hline & Physical, Occupational therapist & $54(18)$ \\
\hline & etc & $105(35)$ \\
\hline \multirow{5}{*}{ Work duration } & $<1$ & $21(7)$ \\
\hline & $1-<5$ & $123(41)$ \\
\hline & $5-<10$ & $69(23)$ \\
\hline & $10-<15$ & $39(13)$ \\
\hline & $\geq 15$ & $48(16)$ \\
\hline \multirow{2}{*}{ Shift work } & 1 time & $255(85)$ \\
\hline & 2 times & $45(15)$ \\
\hline \multirow{4}{*}{ Salary(10,000won) } & $<200$ & $90(30)$ \\
\hline & $200-300$ & $135(45)$ \\
\hline & $300-400$ & $60(20)$ \\
\hline & $>500$ & $15(5)$ \\
\hline \multirow{2}{*}{ Experience of turnover } & No & $156(52)$ \\
\hline & Yes & $144(48)$ \\
\hline
\end{tabular}

\subsection{Factors affecting turnover intention}

The results of the analysis of factors affecting turnover intention are shown in [Table 2]. Model 1 input age, education, marital status, religion, working period, work type, monthly salary, and turnover intention which are the general characteristics as the independent variable. And the marital status and religion were analyzed to process as dummy variables ( 0 . 1). Model 1 showed no significant influence on turnover intention $(\mathrm{F}=1.534, \mathrm{p}=0.122)$ with a $1.6 \%$ explanatory power on turnover intention, meaning that no variables were having significant influence. Model 2 added emotional labor to the independent variables of Model 1, 
and showed significant influence $(\mathrm{F}=18.849, \mathrm{p}=0.000)$. The explanatory power of Model 2 was $35.0 \%$, being found to be significantly influenced by monthly salary $(\beta=-.165, p=.009)$ and emotional labor $(\beta=.593, \mathrm{p}=.000)$. Model 3 additionally input emotional labor and job satisfaction to the independent variables of Model 1, and showed significant influence $(\mathrm{F}=27.614, \mathrm{p}=0.000)$. The explanatory power of Model 3 was $46.5 \%$, being found to be significantly influenced by emotional labor $(\beta=.325, \mathrm{p}=.000)$ and job satisfaction $(\beta=-$ $.433, \mathrm{p}=.000)$. Model 4 additionally input emotional labor, job satisfaction, and organizational commitment to the independent variables of Model 1, and showed significant influence $(\mathrm{F}=34.523, \mathrm{p}=0.000)$. The explanatory power of Model 4 was $54.5 \%$, being found to be significantly influenced by emotional labor $(\mathrm{F}=.301, \mathrm{p}=.000)$, job satisfaction $(\mathrm{F}=-.118$, $\mathrm{p}=.048)$, and organizational commitment $(\beta=-.447, \mathrm{p}=.001)$.

Table 2. Hierarchical multiple regression analysis on the affecting the turnover intention

\begin{tabular}{|c|c|c|c|c|c|c|c|c|c|c|c|c|}
\hline \multirow{2}{*}{ Variables } & \multicolumn{3}{|c|}{ Model 1} & \multicolumn{3}{|c|}{ Model 2} & \multicolumn{3}{|c|}{ Model 3} & \multicolumn{3}{|c|}{ Model 4} \\
\hline & $\beta$ & $\mathrm{t}$ & $\mathrm{p}$ & $\beta$ & $\mathrm{t}$ & $\mathrm{p}$ & $\beta$ & $\mathrm{t}$ & $\mathrm{p}$ & $\beta$ & $\mathrm{t}$ & $\mathrm{p}$ \\
\hline Age(year) & -.148 & -1.458 & .158 & -.060 & -.778 & .453 & -.038 & -.516 & .609 & .046 & .719 & .456 \\
\hline Education & -.037 & -.440 & .678 & -.007 & -.095 & .936 & .009 & .155 & .879 & .006 & .153 & .860 \\
\hline Marital status & -.133 & -1.505 & .146 & -.098 & -1.501 & .131 & -.090 & -1.540 & .126 & -.091 & -1.672 & .092 \\
\hline Religion & .032 & .382 & .720 & .036 & .747 & .463 & .065 & 1.512 & .130 & .063 & 1.659 & .086 \\
\hline Work duration & .112 & .070 & .194 & .145 & 1.624 & .117 & .092 & 1.133 & .264 & .065 & .901 & .357 \\
\hline Shift work & .035 & .417 & 694 & -.048 & -.709 & .484 & -.069 & -1.155 & .247 & -.074 & -1.460 & .133 \\
\hline Salary $(10,000$ won $)$ & -.136 & -1.732 & .089 & -.165 & -2.754 & .009 & -.083 & -1.513 & .144 & -.061 & -1.235 & .204 \\
\hline $\begin{array}{l}\text { Experience of } \\
\text { turnover }\end{array}$ & .079 & 1.284 & .211 & .075 & 1.577 & .118 & .039 & .844 & .401 & .012 & .287 & .772 \\
\hline Emotional Labor & - & - & - & .593 & 12.961 & .000 & .325 & 6.401 & .000 & .301 & 6.313 & .000 \\
\hline Job Satisfaction & - & - & - & - & - & - & -.433 & -8.510 & .000 & -.118 & -1.840 & .048 \\
\hline $\begin{array}{c}\text { Organizational } \\
\text { Commitment }\end{array}$ & - & - & - & - & - & - & & - & - & -.447 & -7.436 & .001 \\
\hline $\mathrm{R} 2$ & \multicolumn{3}{|c|}{.041} & \multicolumn{3}{|c|}{.371} & \multicolumn{3}{|c|}{.488} & \multicolumn{3}{|c|}{.563} \\
\hline Adjusted R2 & \multicolumn{3}{|c|}{.016} & \multicolumn{3}{|c|}{.350} & \multicolumn{3}{|c|}{.465} & \multicolumn{3}{|c|}{.545} \\
\hline $\mathrm{F}$ & \multicolumn{3}{|c|}{1.534} & \multicolumn{3}{|c|}{18.849} & \multicolumn{3}{|c|}{27.614} & \multicolumn{3}{|c|}{34.523} \\
\hline $\mathrm{P}$ & \multicolumn{3}{|c|}{0.122} & \multicolumn{3}{|c|}{0.000} & \multicolumn{3}{|c|}{0.000} & \multicolumn{3}{|c|}{0.000} \\
\hline
\end{tabular}

\section{Implications and conclusions}

It was found that monthly salary among general characteristics had a significant negative (+) influence on turnover intention. The result of Lee et al.'s study [4] on organizational commitment, job satisfaction, turnover intention, and customer-oriented relationships of the 
medical technology workers at general hospitals showed that monthly income and age had a significant influence on turnover intention. Lee et al. [5] who studied medical technology workers with emotional labor, empowerment, job exhaustion, and turnover intention presented that age, monthly income, and shift work had a significant influence on turnover intention. And the results of Wi et. Al's study [6] showed that working department and position influenced turnover intention. As a result of analyzing this study and the preceding study, it can be concluded that the general characteristic variables having a common significant influence on turnover intention are monthly salary, age, shift work, and working department [7].

Recently, the medical environment has been exposed to the era of infinite competition, and medical technology workers, the professionals in contact with patients and caregivers at hospital, has become an important factor in determining the quality and competitiveness of medical services. This study showed that the emotional labor of the medical technology workers reduced job satisfaction and organizational commitment, and affected turnover intention. These results provide important implications for the management of hospitals, human resources, and organizations, so further in-depth research will be continuously carried out in the future.

\section{References}

[1] H.J. Kim and D.H, Park, "The effects of workplace bullying on turnover intention in hospital nurses," Journal of Digital Convergence, vol.14, no.1, pp.241-252, (2016)

[2] Mandziy Tatiana1, Choi W.H., and Jun J.K., "The effects of medical tourism coordinator service quality perceived by Russian tourists on satisfaction and behavioral intention", Journal of The Korean Data Analysis Society, vol.18, no.2, pp. 891-902, (2016)

[3] S.H. Yoon, "The effects of organizational managerial characteristics and job characteristics on job stress and job effectiveness: A survey on clinical nurses," The Korean Journal of Psychology, vol.7, no.3, pp.451-466, (2004)

[4] S.K. Cha, Y.S. Shin, K.Y. Kim, B.Y. Lee, S.Y. Ahn, and H.S. Jang, "The degrees of emotional labor and it's related factors among clinical nurses,” Journal of Korean Clinical Nursing Research, vol.15, no.2, pp.23-35, (2009)

[5] Kanasz, T. and Zieliñska I., "Emotional labor of the polish social workers: The study in the sociology of emotions." Polish Sociological Review, vol.199, no.3, pp.351-366, (2017)

[6] Lavee, E. and Strier, R., "Social workers' emotional labor with families in poverty: Neoliberal fatigue?" Child \& Family Social Work, vol.23, no.3, pp.504-512, (2018)

[7] I.S. Kim, "The role of self-efficacy and social support in the relationship between emotional labor and burnout, turn over intention among hospital nurses," Journal of Korean Academy of Nursing Administration, vol.15, no.4, pp.515-526, (2009) 
Impact of Emotional Labor on the Turnover Intention of Medical Technology Workers in General Hospital

This page is empty by intention. 